D) Check for updates

Cite this: Org. Biomol. Chem., 2021, 19, 7202

Received 4th May 2021,

Accepted 5th August 2021

DOI: 10.1039/d1ob00871d

rsc.li/obc

\title{
Nucleophilic catalysis of $p$-substituted aniline derivatives in acylhydrazone formation and exchange $\uparrow$
}

\author{
Andrea Canal-Martín, $\$^{\mathrm{a}}$ Claudio D. Navo, (iD † Elena Sáez, ${ }^{\mathrm{c}}$ Dolores Molero, ${ }^{\mathrm{b}}$ \\ Gonzalo Jiménez-Osés (iD *b,d and Ruth Pérez-Fernández (iD *a
}

\begin{abstract}
Hydrazone bond formation is a versatile reaction employed in several research fields. It is one of the most popular reversible reactions in dynamic combinatorial chemistry. Under physiological conditions, hydrazone exchange benefits from the addition of a nucleophilic catalyst. We report a mechanistic study and superior performance of electron-rich $p$-substituted aniline derivatives as catalysts for efficient hydrazone formation and exchange in both protic and aprotic solvents. Rigorous kinetic analyses demonstrate that imine formation with 3-hydroxy-4-nitrobenzaldehyde and aniline derivatives proceeds with unprecedented third-order kinetics in which the aldehyde consistently shows a partial order of two. Computational investigations provide insights into the mechanisms of these transformations.
\end{abstract}

\section{Introduction}

Hydrazone bond formation is a versatile reaction employed in bioconjugation, polymer functionalization, peptide ligation, metal sensing, dyes, and medicinal and supramolecular chemistry amongst others. ${ }^{1-12}$ The hydrazone group's popularity has been attributed to its easy synthesis and distinctive structural properties such as (i) the isomerism of the $\mathrm{C}=\mathrm{N}$ bond, (ii) the stability to hydrolysis of the $\mathrm{C}=\mathrm{N}$ bond under neutral conditions due to its mesomeric effect, (iii) an imine carbon that has both electrophilic and nucleophilic characters; and (iv) an acidic NH proton used in anion sensing, metal coordination or intramolecular H-bonding. ${ }^{13}$

However, despite the appealing hydrazone bond properties, the relatively slow rate of its formation under physiological conditions has limited its applications (Fig. 1).

Over the last fifteen years, several groups have used nucleophilic catalysts to speed up this reaction, including aniline as a catalyst. $^{14-16}$

\footnotetext{
${ }^{a}$ Structural and Chemical Biology Department, Centro de Investigaciones Biológicas Margarita Salas, CIB-CSIC, Madrid 28040, Spain.E-mail: ruth.perez@csic.es ${ }^{b}$ Center for Cooperative Research in Biosciences (CIC bioGUNE), Basque Research and Technology Alliance (BRTA), Bizkaia Technology Park, Building 800, 48160 Derio, Spain.E-mail: gjoses@cicbiogune.es

${ }^{c}$ CAI de RMN, Universidad Complutense de Madrid, 28040 Madrid, Spain

${ }^{d}$ Ikerbasque, Basque Foundation for Science, 48013 Bilbao, Spain

$\dagger$ Electronic supplementary information (ESI) available: NMR spectra, MS, computational data, kinetic experiments and equations. See DOI: 10.1039/ d1ob00871d

$\$$ These authors contributed equally to the work.
}

Early comparative polarimetric studies of kinetics and mechanisms regarding hydrazone, semicarbazone and oxime formation were reported by Stempel et al. in the 1940s. ${ }^{17}$ Mechanistic studies on semicarbazone and oxime formation provided by Jencks in the $1960 \mathrm{~s}^{18}$ showed that the rate-limiting reaction was the condensation of the substrate with the catalyst to form the activated imine, prior to the transimination reaction. Studies showing how the structural features of aldehydes and hydrazines influence the hydrazone reaction ${ }^{19,20}$ and the hydrolytic stability of the hydrazone bond ${ }^{21}$ have been reported.

On the other hand, hydrazone exchange has been extensively used in dynamic combinatorial chemistry (DCC), being one of the most popular reversible chemistries. ${ }^{22,23}$ DCC is based on adaptive molecular networks, named dynamic combinatorial libraries (DCLs), which under thermodynamic control and through reversible bonds respond to external stimuli. Protein-directed DCC has been proven to be an excel-

a

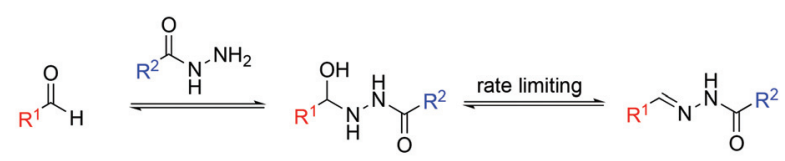

b

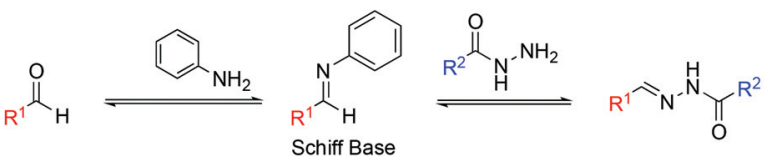

Fig. 1 Acylhydrazone formation for DCC at physiological pH (a) in the absence and (b) in the presence of aniline as a catalyst. 
lent tool to speed up the drug discovery process allowing the protein target to find its best ligand in situ. ${ }^{24}$ We are interested in the application of hydrazone exchange under physiological conditions to protein-directed dynamic combinatorial systems. Acidic conditions were used to speed up bond formation and cleavage until the addition of aniline as a nucleophilic catalyst for acylhydrazone DCC at physiological $\mathrm{pH}$ was reported. ${ }^{25,26}$ Mechanistically, aniline reacts with the aldehyde as a nucleophilic catalyst to form an aromatic Schiff base intermediate (Fig. 1b). This intermediate acts as an electrophile. The higher reactivity of Schiff bases compared to that of their parent aldehydes toward nitrogen nucleophiles enables the transimination step to achieve the hydrazone/acylhydrazone exchange. Nevertheless, the requirement of a high concentration of aniline and its toxicity reported in cells prompted the search for alternative catalysts. ${ }^{27-30}$ Note that in catalyzed DCC, unlike in conventional catalysis, the amount of catalyst used is not limited to substoichiometric concentrations. ${ }^{31}$

Recently, modelling studies on hydrazone exchange in the absence of a catalyst supported the hypothesis that the ratelimiting step in hydrazone exchange is the nucleophilic attack on the protonated hydrazone, ${ }^{32,33}$ whereas in hydrazone formation the rate-limiting step in water at neutral $\mathrm{pH}$ was the cleavage of the carbinolamine intermediate to eliminate water. $^{18 c}$

Studies regarding the effectiveness of nucleophilic catalysts in aqueous solvents have been reported and the reaction rate of the global process is described, assuming that the imine formation is always the rate-limiting step. ${ }^{18 c, 34}$ Nonetheless, the acylhydrazone formation mechanism has been rarely studied as a multistep process.

Here we present a detailed study of three different $p$-substituted aniline derivatives compared to aniline in acylhydrazone formation. We performed kinetic studies by NMR spectroscopy on imine and acylhydrazone formation as separate reactions in a polar aprotic solvent (acetonitrile) in analogy to previous reports. $^{35}$ Furthermore, the acylhydrazone reaction was performed in water in the absence and presence of the catalysts, and in a dynamic combinatorial chemistry system which confirmed the efficiency of $p$-toluidine and $p$-anisidine in acylhydrazone exchange at physiological $\mathrm{pH}$ and low temperatures.

\section{Results and discussion}

The kinetics of the reaction between aldehyde 1 (50 mM) and acylhydrazide $2(29 \mathrm{mM})$ in the absence of a catalyst was first analyzed by ${ }^{1} \mathrm{H}$ NMR spectroscopy in anhydrous $\mathrm{CD}_{3} \mathrm{CN}$ at $288 \mathrm{~K}$ (Fig. 2 and the ESI $\dagger$ ). Acetonitrile was selected as a convenient aprotic and anhydrous solvent to ensure complete solubilization of the reagents and avoid hydrolysis of the formed hydrazone.

A dynamic equilibrium between both reagents and the corresponding hemiaminal intermediate (HA) was reached before the first experiment was performed, yielding a ratio of around $4: 2: 1$ of compounds $1: 2:$ HA, respectively. This ratio

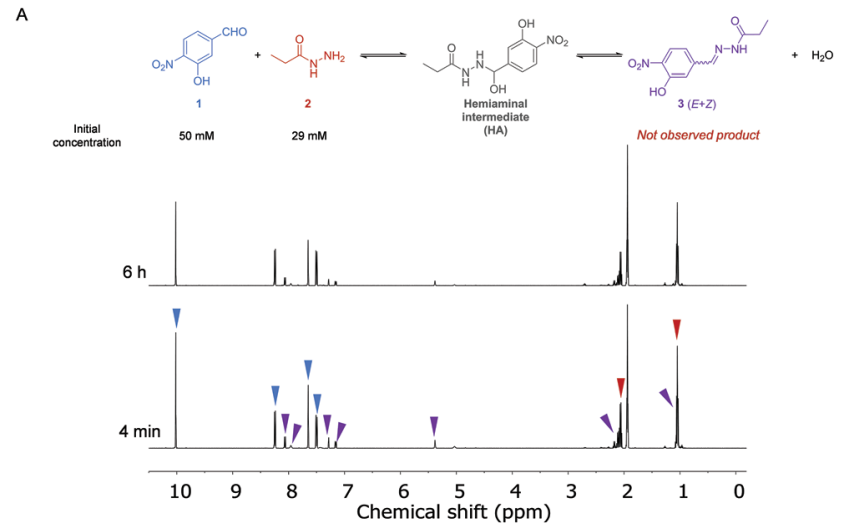

Fig. 2 (A) Reaction between aldehyde 1 and acylhydrazide 2 in $\mathrm{CD}_{3} \mathrm{CN}$ to form acylhydrazone $3 .{ }^{1} \mathrm{H}$ NMR $(500 \mathrm{MHz}, 288 \mathrm{~K})$ spectra at different reaction times. Blue, red and purple arrows indicate the signals of compounds 1, 2 and $\mathrm{HA}$, respectively.

was maintained, and no new signals appeared after more than $5 \mathrm{~h}$, indicating that the subsequent dehydration reaction to form the final acylhydrazone 3 did not take place at a measurable rate. From these data, the equilibrium constant for the first step of the imine formation reaction and, thus the ratio between the forward $\left(k_{1}\right)$ and reverse $\left(k_{-1}\right)$ reaction rates was found to be: $K_{\mathrm{eq}}=k_{1} / k_{-1}=12.7 \mathrm{M}^{-1}$.

The same reaction between aldehyde $\mathbf{1}$ and acylhydrazide $\mathbf{2}$ was then analyzed in the presence of different aniline derivatives $\mathbf{4 a - d}$ as catalysts, namely $\mathbf{4 a}$ : aniline, $\mathbf{4 b}$ : $p$-toluidine, $\mathbf{4 c}$ : $p$-anisidine and $\mathbf{4 d}$ : $p$-bromoaniline. For a better understanding of the global process the two consecutive reactions, namely imine formation between aldehyde $\mathbf{1}$ and aniline derivatives 4a-d and subsequent imine exchange with acylhydrazide 2 to yield acylhydrazone 3, were studied separately (Fig. 3). The estimated reaction rate constants for all the studied reactions are summarized in Table 1.

For the first reaction (i.e. imine formation), compounds 5ad formed smoothly at measurable reaction rates, and no signals corresponding to the hemiaminal intermediates (HA) were observed in the NMR spectra. This suggests that a fastdynamic equilibrium between reagents $\mathbf{1}$ and $\mathbf{4 a - d}$ and the corresponding hemiaminal intermediates is reached in which the reverse nucleophilic addition reaction is much faster than the forward process, and that elimination of water from intermediates is also fast.

By performing the reactions using different sets of initial concentrations for the reagents and using the initial rate method, an unexpected partial order of 2 for aldehyde 1 and an expected order of 1 for anilines $\mathbf{4 a - d}$ were determined. To the best of our knowledge, such a second-order character in aldehydes has been only reported for processes involving nucleophilically activated aromatic aldehydes such as the Cannizaro $^{36}$ and benzoin condensation ${ }^{37}$ reactions. Possible mechanistic explanations for this behavior, including catalysis by a benzoic derivative of aldehyde 1 (labelled as $\mathbf{1}^{\prime}$, see below) are summarized in the ESI. $\uparrow$ Third-order integrated rate laws 


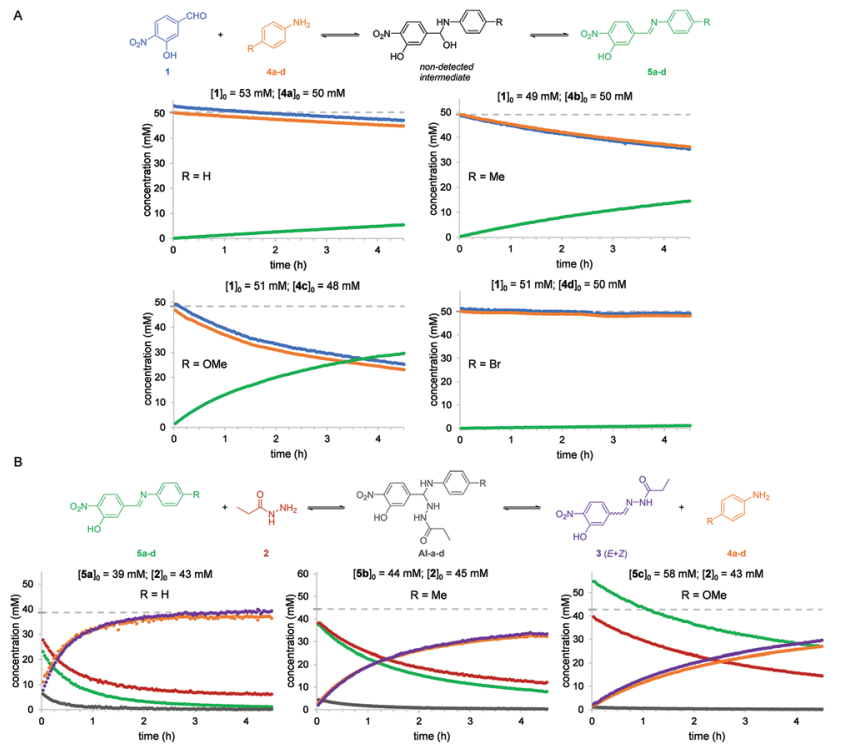

Fig. 3 (A) Reaction between aldehyde 1 and anilines $4 a-d$ in $C D_{3} C N$ to form imines $5 a-d$. Plots show the concentrations $(\mathrm{mM})$ of compounds $1,4 a-d$ and $5 a-d$ at different reaction times using approximately equal initial concentrations of reagents 1 and $4 a-d$. Grey dashed lines indicate the initial concentrations of the limiting reagents for each reaction. (B) Reaction between imines $5 a-d$ and acylhydrazide 2 in $C_{3} C N$ to form acylhydrazone 3 as a mixture of $Z / E$ isomers. Plots show the concentrations $(\mathrm{mM})$ of compounds $4 \mathrm{a}-\mathrm{c}, 3$ and $5 \mathrm{a}-\mathrm{c}$ at different reaction times using approximately equal initial concentrations of reagents $5 a-c$ and 3. Grey dashed lines indicate the initial concentrations of the limiting reagents for each reaction. Imine $5 \mathrm{~d}$ was discarded due to its poor solubility in $\mathrm{CD}_{3} \mathrm{CN}$ at the concentrations required for NMR analysis.

Table 1 Estimated reaction rate constants $\left(k_{\text {obs }}\right)$ for the reactions between aldehyde 1 and anilines $4 a-d$ to form imines $5 a-d$, and the subsequent reactions of these imines with acylhydrazide 2 to form acylhydrazone 3. n.d.: not determined. For experimental and theoretical details on the derivation of these parameters, see the ESI $\dagger$

\begin{tabular}{llll}
\hline Aniline & $\mathrm{R}$ & $\begin{array}{l}\text { Reaction } \mathbf{1}+\mathbf{4 a}-\mathbf{d} \\
k_{\text {obs }}\left(\mathrm{M}^{-2} \mathrm{~s}^{-1}\right)\end{array}$ & $\begin{array}{l}\text { Reaction } \mathbf{5 a - d}+\mathbf{2} \\
k_{\mathrm{obs}}\left(\mathrm{M}^{-2} \mathrm{~s}^{-1}\right)\end{array}$ \\
\hline $\mathbf{4 a}$ & $\mathrm{H}$ & $0.0030 \pm 0.0026$ & $0.5795 \pm 0.3887$ \\
$\mathbf{4 b}$ & $\mathrm{Me}$ & $0.0107 \pm 0.0020$ & $0.0686 \pm 0.0476$ \\
$\mathbf{4 c}$ & $\mathrm{OMe}$ & $0.0365 \pm 0.0093$ & $0.0521 \pm 0.0252$ \\
$\mathbf{4 d}$ & $\mathrm{Br}$ & $0.0006 \pm 0.0013$ & n.d.
\end{tabular}

for reactions in which the initial concentrations were either different or equal were derived, which allowed the estimation of the observed reaction rate constants; $k_{\text {obs }}$ (see the ESI $\dagger$ ). As expected, the reaction with $p$-anisidine $\mathbf{4 c}$ was observed to be the fastest process due to its higher nucleophilic character $\left(k_{\text {obs }}=0.0365 \mathrm{M}^{-2} \mathrm{~s}^{-1}\right)$, while the reactions with the other aniline derivatives were 3 to 61 times slower (Table 1 ).

Identical analyses were performed for the second reaction in the global aniline-catalyzed process, namely the reaction between acylhydrazide 2 and freshly synthesized and purified imines $\mathbf{5 a - c . ~ I m i n e ~} \mathbf{5 d}$ was discarded due to its poor solubility in $\mathrm{CD}_{3} \mathrm{CN}$ at the concentrations required for NMR analysis, which precluded obtaining reliable and reproducible initial concentration values. Before the first experiment was performed, a fast-dynamic equilibrium was reached between both reagents and the corresponding aminal intermediates (AI-a-c), which could be detected by ${ }^{1} \mathrm{H}$ NMR in nearly all cases (Fig. 3 and the ESI $\dagger$ ). The final acylhydrazone 3 was then steadily formed as a mixture of $Z / E$ isomers from the corresponding intermediates. This reaction mechanism was also found to be second-order in the imine and first-order in the acylhydrazide, although the deviation from integer partial orders was quite significant in some cases such as with imine 5a. As a consequence, the resulting third-order integrated rate laws provided quite different $k_{\text {obs }}$ values depending on the initial concentrations of the reagents and thus such values must be taken with caution. As expected, the reaction with the imine derived from $p$-anisidine $5 \mathbf{c}$ was observed to be the slowest one due to its poor electrophilic character $\left(k_{\mathrm{obs}}=0.0521 \mathrm{M}^{-2} \mathrm{~s}^{-1}\right)$ (Table 1). Nevertheless, as can be seen in Fig. 3, when nearly equimolecular concentrations of reactants were used, it was clear that this second reaction (i.e. acylhydrazone formation) was always faster than the first reaction (i.e. imine formation), which is rate-limiting in all cases.

Anilines para-substituted with electron-donating groups $\mathbf{4 b}$ $(\mathrm{R}=\mathrm{Me})$ and $4 \mathrm{c}(\mathrm{R}=\mathrm{OMe})$ were determined to be the most effective catalysts for the global reaction between aldehyde $\mathbf{1}$ and acylhydrazide 2 in acetonitrile solution. In fact, predicting the consequences of varying the electronic properties of the substituents at the para position of aniline catalysts is not trivial in this type of multi-step reaction. On one hand, for the first reaction (imine formation) electron-donating substituents ( $p$-OMe and $p$-Me) are expected to lower the activation barriers for the initial nucleophilic attack on the aldehyde and, to a lower extent, for water elimination (i.e. the lone electron pairs of the nitrogen atom are more localized and thus more available for forming the double $\mathrm{C}=\mathrm{N}$ bond). On the other hand, for the second reaction (hydrazone formation), electron-donating substituents ( $p$-OMe and $p$-Me) are expected to increase the activation barriers for the nucleophilic attack of the acylhydrazide on the imine (i.e. imines are less electrophilic) and aniline elimination (i.e. the anilines are worse leaving groups). Thus, since so many equilibria and microkinetic steps are involved in the global reaction, the effects of the aniline substituents on the global reaction rate will be determined by the rate-limiting step (i.e. the step with the highest activation barrier). The observation that electron-rich anilines ( $p$-OMe and $p-\mathrm{Me}$ ) accelerate the global reaction indicates that the ratelimiting steps occur at the first reaction (i.e. formation of the imine), either in the initial nucleophilic attack on the aldehyde or water elimination steps. Performing the reaction in different solvents (i.e. aqueous or not aqueous) can affect the relative rates of each step, water elimination being expected to be unfavored in aqueous solvents as previously reported. Our results stress the importance of studying the accelerating properties of a given catalyst in the different sequential reaction steps, and are in good agreement with the results observed in aqueous solvents with similar reagents (vide infra). 
The mechanism of hydrazone exchange in the presence of aniline catalysts was further studied through quantum mechanical calculations in an implicit solvent (acetonitrile) at the $\mathrm{SMD}\left(\mathrm{CH}_{3} \mathrm{CN}\right) / \mathrm{M} 06-2 \mathrm{X} / 6-311++\mathrm{G}(2 \mathrm{~d}, \mathrm{p}) / / \mathrm{PCM}\left(\mathrm{CH}_{3} \mathrm{CN}\right) / \mathrm{M} 06-$ $2 \mathrm{X} / 6-31+\mathrm{G}(\mathrm{d}, \mathrm{p})$ level (see Computational details and the ESI $\dagger$ ). For the initial imine formation reaction (i.e. condensation of aldehyde 1 with anilines) no transition structures describing the direct nucleophilic addition to the aldehyde carbonyl group - either in its protonated or neutral forms - could be located. However, assisting the nucleophilic attack with protic molecules acting as proton shuttles, such as water, the orthonitrophenol moiety of aldehyde $\mathbf{1}$ or a benzoic acid derivative generated from or present as an impurity of aldehyde 1 not detected by ${ }^{1} \mathrm{H}$ NMR (labelled as $\mathbf{1}^{\prime}$ ), ${ }^{38-40}$ did allow locating feasible transition structures for both the nucleophilic addition (ts1 a-d) and water elimination (ts2 a-d) elementary steps (see the ESI $\dagger$ ). Hence, catalysis by the benzoic acid derivative $\mathbf{1}^{\prime}$ yielded the lowest activation barriers $\left(\Delta G^{\ddagger}\right)$ for these processes and, more importantly, suggested that water elimination is the rate-limiting step to yield imines $\mathbf{5 a - d}$ in agreement with previous reports ${ }^{17,18}$ and reproduced the experimental reactivity trends: $\Delta G^{\ddagger}\left(\right.$ ts2 c) $<\Delta G^{\ddagger}\left(\right.$ ts2 b) $<\Delta G^{\ddagger}$ (ts2 a) $<\Delta G^{\ddagger}$ (ts2 d) (Fig. 4).

Such a catalytic effect of acid $\mathbf{1}^{\prime}$ would provide a plausible explanation for the experimentally observed partial order of 2 for aldehyde $\mathbf{1}$. Assuming that the concentration of acid $\mathbf{1}^{\prime}$ at a given reaction time is a fraction $(\chi)$ of the concentration of aldehyde $1\left(\left[\mathbf{1}^{\prime}\right]=\chi[\mathbf{1}]\right)$, third-order reaction rate equations could be written as: rate $=k\left[\mathbf{1}^{\prime}\right][\mathbf{1}][\mathbf{a}-\mathbf{d}]=k \cdot \chi[\mathbf{1}]^{2}[\mathbf{a}-\mathbf{d}]$.

Thermodynamics is also well represented by this model, indicating that (a) the hemiaminal intermediate formation is an endergonic process (and thus not experimentally detectable) and (b) the formation of the stable imine products (the $E$ isomers being much more stable) is either thermoneutral or slightly endergonic, suggesting microscopic reversibility.

Stationary points (i.e. transition structures and energy minima) could also be located for the second reaction (i.e. nucleophilic attack of an abbreviated model of acylhydrazide $\left(2^{\prime}\right)$ followed by aniline cleavage) starting from protonated iminium intermediates $\left(5^{+} \mathbf{a}-\mathbf{d}\right)$ (Fig. 5 and the ESI $\dagger$ ). It is noteworthy that the transition states of none of the elementary steps were involved in this reaction (i.e. nucleophilic attack of acylhydrazide and aniline cleavage could be computed unless the $\mathrm{C}=\mathrm{N}$ bonds of the reacting imines were protonated as iminium ions $\left(\mathrm{C}=\mathrm{NH}^{+}\right)$). Given the lack of experimental $\mathrm{p} K_{\mathrm{b}}$ values for imines $\mathbf{5 a - d}$ or similar compounds, the energy penalty associated with the formation of such iminium species $\left(5^{+}\right.$a-d) in acetonitrile was estimated indirectly using combinations of machine learning approaches and experimental data $^{41-44}$ (see the ESI $\dagger$ ). However, considering the insufficient accuracy of these estimations, we were more interested in the intrinsic activation energies involved in the process. Although the transition states for the nucleophilic addition (ts3 a-d) and aniline cleavage (ts4 a-d) were calculated to be very close in energy, the activation barriers for the latter step were ratelimiting in all cases, with values following the trend observed experimentally: $\Delta G^{\ddagger}\left(\right.$ ts4 c) $>\Delta G^{\ddagger}\left(\right.$ ts4 b) $>\Delta G^{\ddagger}\left(\right.$ ts4 a) $>\Delta G^{\ddagger}$ (ts4 d). In agreement with the NMR experiments described above that allowed the detection of transient species, stable protonated aminal intermediates $\left(\mathbf{A I}^{+} \mathbf{a}-\mathbf{d}\right)$ after the addition of a model acylhydrazide were calculated for all studied cases involving derivatives from aniline, $p$-toluidine, $p$-anisidine and
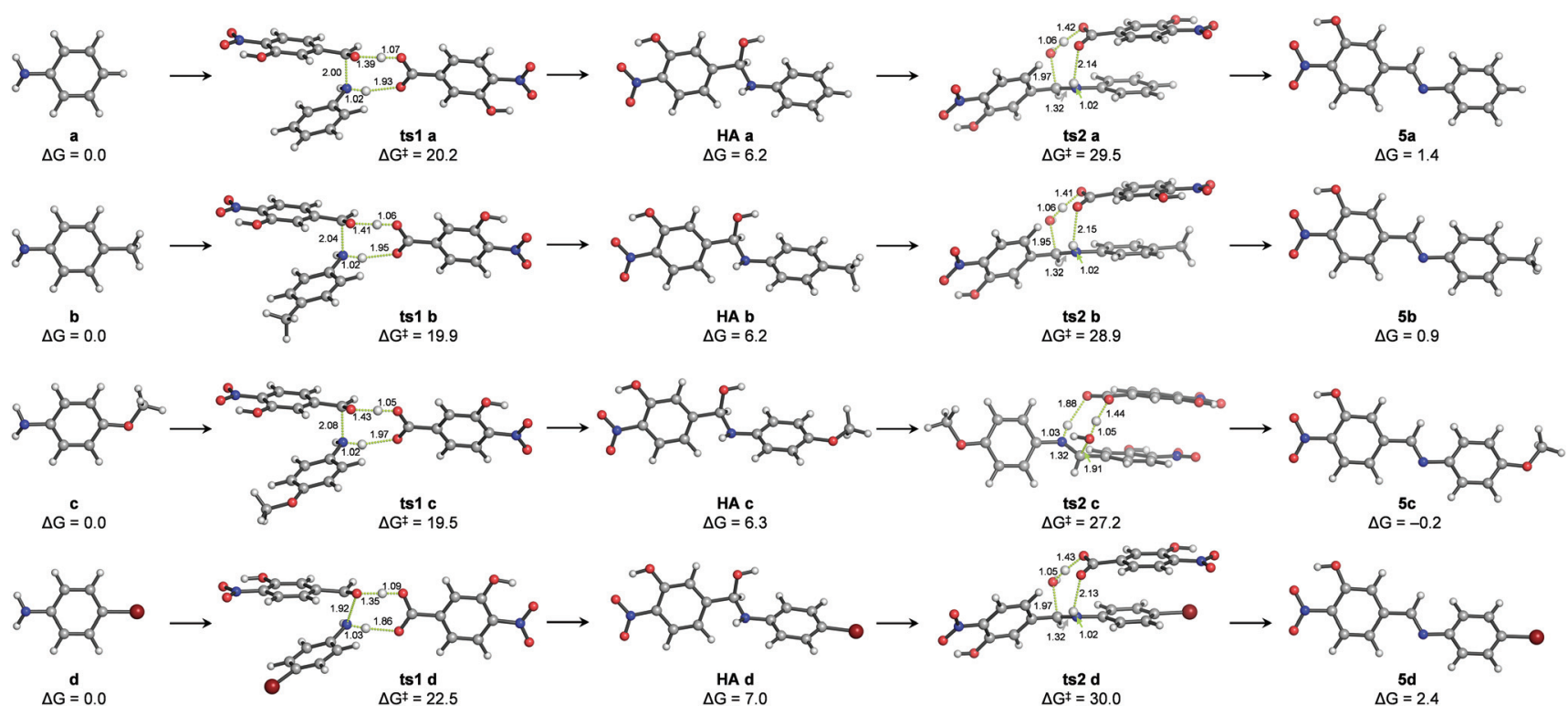

Fig. 4 Lowest-energy structures calculated with $\mathrm{SMD}\left(\mathrm{CH}_{3} \mathrm{CN}\right) / \mathrm{M} 06-2 \mathrm{X} / 6-311++\mathrm{G}(2 \mathrm{~d}, \mathrm{p}) / / \mathrm{PCM}\left(\mathrm{CH}_{3} \mathrm{CN}\right) / \mathrm{M} 06-2 \mathrm{X} / 6-31+\mathrm{G}(\mathrm{d}, \mathrm{p})$ for the nucleophilic addition of anilines $\mathrm{a}-\mathrm{d}$ to aldehyde 1 (ts1 a-d), the corresponding hemiaminal intermediates ( $\mathrm{HA} a-d)$ and subsequent water elimination (ts2 $a-d)$ to yield imines $5 a-d$. Both elementary steps are catalyzed with the benzoic acid derivative $1^{\prime}$ (see the main text). Relative free energies ( $\left.\Delta G\right)$ from the separated reactants are given in $\mathrm{kcal} \cdot \mathrm{mol}^{-1}$ and distances are given in Angstrom. 

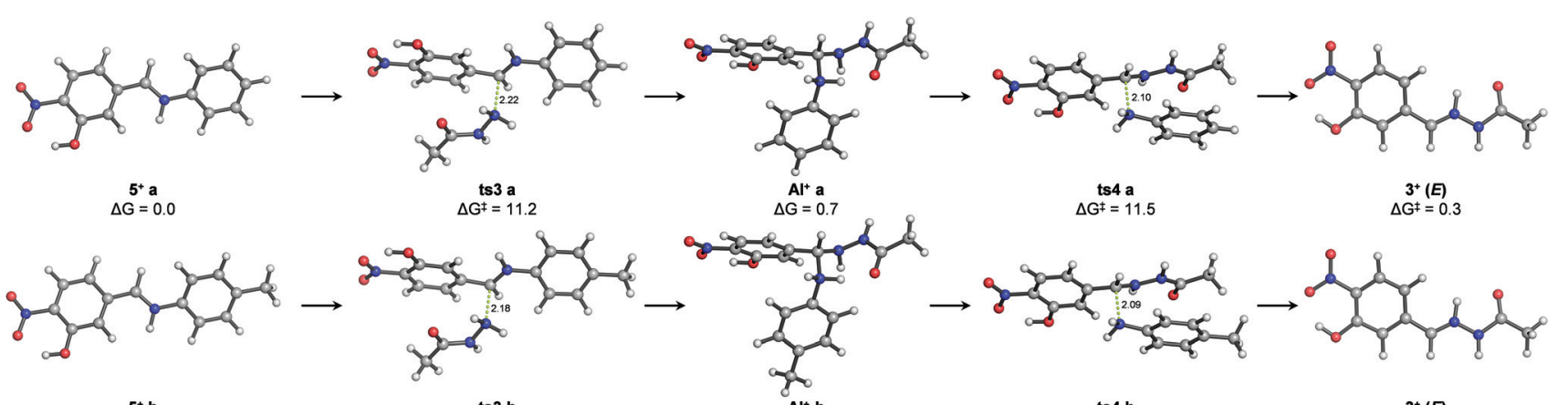

$\Delta \mathrm{G}^{\ddagger}=11.5$

$3^{+}(E)$
$\Delta G^{\ddagger}=0.3$

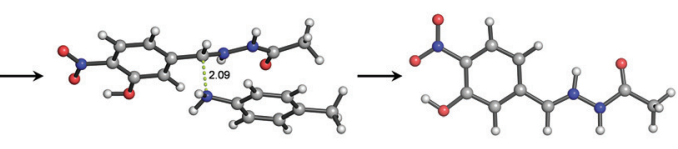

$\begin{array}{ccc}\mathbf{5}^{+} \mathbf{b} & \mathbf{t s} \mathbf{b} & \mathbf{\mathbf { A l } ^ { + } \mathbf { b }} \\ \Delta \mathrm{G}=0.0 & \Delta \mathrm{G}^{ \pm}=11.6 & \Delta \mathrm{G}=1.0\end{array}$

$\begin{array}{cc}\mathbf{A l}^{+} \mathbf{b} & \mathbf{t s} \mathbf{b} \\ \Delta G=1.0 & \Delta \mathbf{G}^{ \pm}=12.2\end{array}$

ts4 b
$\Delta G^{ \pm}=12.2$$\quad \begin{gathered}\mathbf{3}^{+}(\boldsymbol{E}) \\ \Delta \mathrm{G}^{ \pm}=1.6\end{gathered}$
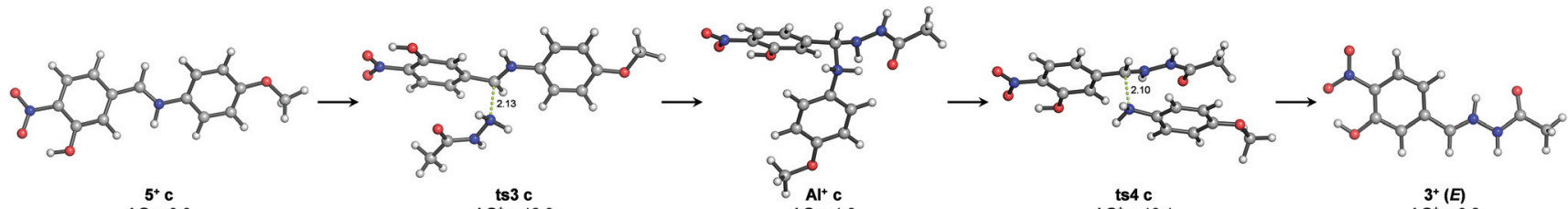

$\mathbf{5}^{+} \mathbf{c}$
$\Delta \mathrm{G}=0.0$

ts $3 \mathbf{c}$
$\Delta \mathrm{G}^{ \pm}=12.3$

$\mathbf{A l}^{+} \mathbf{c}$
$\Delta G=1.3$

ts $4 \mathbf{c}$
$\Delta G^{ \pm}=13.1$

$3^{+}(E)$
$\Delta \mathrm{G}^{ \pm}=3.2$
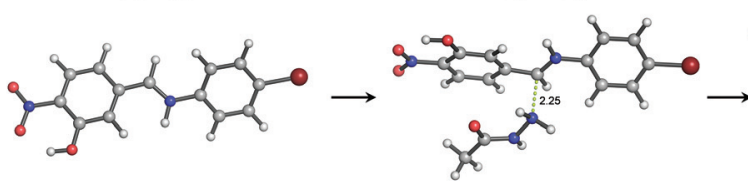

$\mathbf{5}^{+} \mathbf{d}$
$\Delta G=0.0$

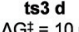

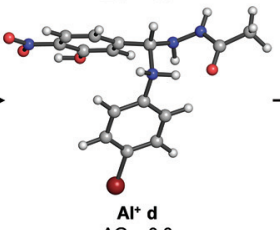

$\mathbf{A l}^{+} \mathbf{d}$
$\Delta G=0.0$
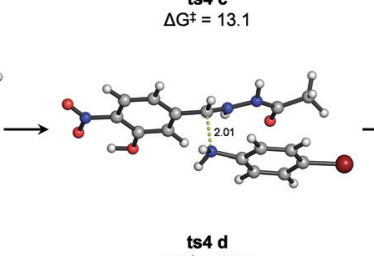

ts4 d
$\Delta \mathrm{G}^{\ddagger}=10.8$

Fig. 5 Lowest-energy structures calculated with $\mathrm{SMD}\left(\mathrm{CH}_{3} \mathrm{CN}\right) / \mathrm{M} 06-2 \mathrm{X} / 6-311++\mathrm{G}(2 \mathrm{~d}, \mathrm{p}) / / \mathrm{PCM}\left(\mathrm{CH}_{3} \mathrm{CN}\right) / \mathrm{M} 06-2 \mathrm{X} / 6-31+\mathrm{G}(\mathrm{d}, \mathrm{p})$ for the nucleophilic addition of acylhydrazide to iminium derivatives im a-d (ts3 a-d), the corresponding protonated aminal intermediates (Al ${ }^{+}$a-d) and subsequent water elimination (ts 4 a-d) to yield hydrazone 3 (only the $E$ isomer is shown). Relative free energies $(\Delta G)$ from the separated reactants are given in $\mathrm{kcal} \cdot \mathrm{mol}^{-1}$ and distances are given in Angstrom.

$p$-bromoaniline. Also in agreement with the experimental observations, both the $Z$ and $E$ isomers of the protonated hydrazone $\left(3^{+}\right)$were calculated to have similar energies, the latter being slightly more stable. As in the imine formation reaction, hydrazone formation is also either thermoneutral or slightly endergonic, suggesting microscopic reversibility. Calculations in implicit water yielded virtually identical results, with differences in the relative energies of the calculated stationary points smaller than $1 \mathrm{kcal} \mathrm{mol}^{-1}$ (see the ESI $\dagger$ ). As a referee noted, water and protic solvents could change the reaction mechanism acting as a proton shuttle and/or favoring the elimination of hydroxide ions from carbinolamine intermediates, ${ }^{45}$ although such theoretical predictions have not been confirmed experimentally. ${ }^{46,47}$

To study the performance of the catalysts at physiological $\mathrm{pH}$, the reaction between aldehyde $\mathbf{1}(0.09 \mathrm{mM})$ and acylhydrazide $6(0.9 \mathrm{mM})$ to yield acylhydrazone 7 was performed according to our previous work in a Tris buffer solution, using an excess of acylhydrazide to achieve fast conversion at reasonable reaction times. ${ }^{30}$ To monitor the reaction progress by HPLC-MS, an acylhydrazide with a chromophore group, like compound 6, was selected (Fig. 6).

The performance of amines $4 \mathbf{4 a - d}$ as catalysts was monitored for 1 week and compared to the uncatalyzed reaction (Fig. 6a). The time-course of the reaction during the first $6 \mathrm{~h}$ is shown in Fig. $6 \mathrm{~b}$. The reaction in the presence of the catalyst

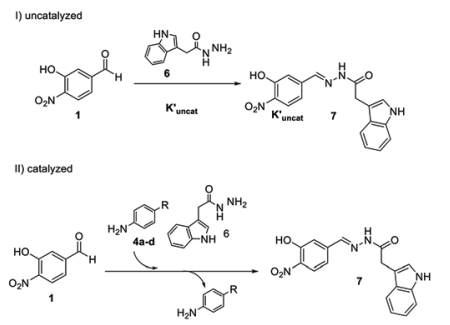

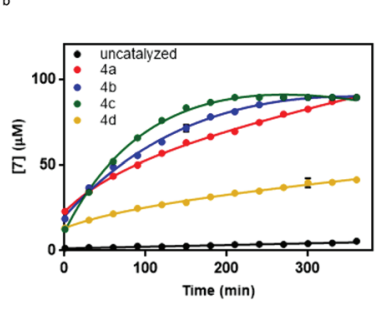

Fig. 6 Acylhydrazone formation in the absence and presence of a nucleophilic catalyst in aqueous buffer solution. Reaction conditions: aldehyde $1(0.09 \mathrm{mM})$, acylhydrazide $6(0.9 \mathrm{mM}), 20 \mathrm{mM}$ Tris buffer $(\mathrm{pH}$ 7.8), $T=6{ }^{\circ} \mathrm{C}, 5 \%$ DMSO. (a) Acylhydrazone reaction mechanism. (b) Time course formation of acylhydrazone 7 in the absence of the catalyst (black dots), and in the presence of $15 \mathrm{mM}$ aniline (red dots), $p$-toluidine (green dots), $p$-anisidine (blue dots) and $p$-bromoaniline (yellow dots). Experiments were performed in triplicate and the mean \pm SD values are represented in the plot.

was completed between 3 hours and 4 days depending on the catalyst ( $5.5 \mathrm{~h}$ for $\mathbf{4 a}, 4 \mathrm{~h}$ for $\mathbf{4 b}, 3 \mathrm{~h}$ for $\mathbf{4 c}$, and 4 days for $\mathbf{4 d}$ ). It is noteworthy that the two best catalysts in aqueous buffer solutions, namely, $\mathbf{4 b}(\mathrm{R}=\mathrm{Me})$ and $\mathbf{4 c}(\mathrm{R}=\mathrm{OMe})$, also exhibited the fastest kinetics in acetonitrile, thus validating the initial predictions and mechanistic studies despite the different reaction conditions used. 


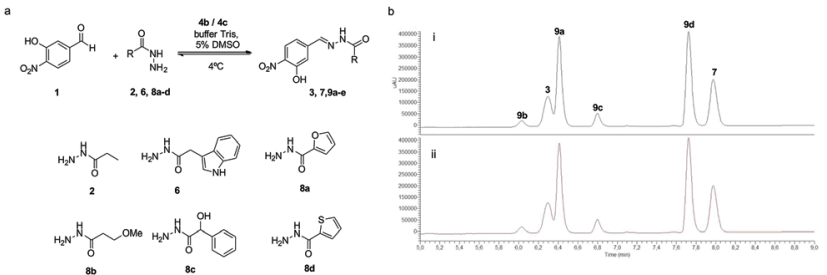

Fig. 7 DCL catalyzed by $4 \mathrm{~b}$ and $4 \mathrm{c}$ in an aqueous buffer solution. (a) Aldehyde 1 and acylhydrazides 2, 6 and $8 a-d$ as building blocks. (b) DCLs in the presence of $4 \mathrm{~b}$ (i) and $4 \mathrm{c}$ (ii). Reaction conditions: aldehyde $1(90 \mu \mathrm{M})$, acylhydrazide 2,6 , and $8 \mathrm{a}-\mathrm{d}(6 \times 270 \mu \mathrm{M}), 4 \mathrm{~b}$ or $4 \mathrm{c}(15 \mathrm{mM})$, $20 \mathrm{mM}$ Tris buffer $\left(\mathrm{pH} \mathrm{7.8)}, \mathrm{T}=6^{\circ} \mathrm{C}, 5 \%\right.$ (v/v) DMSO.

In a dynamic combinatorial library, a particular challenge of hydrazone chemistry at physiological $\mathrm{pH}$ lies in the efficiency of achieving the exchange process. After establishing $p$-toluidine (4b) and $p$-anisidine (4c) as the most efficient catalysts for acylhydrazone formation in water, the DCC approach was attempted by mixing aldehyde $\mathbf{1}$ (Fig. 7) with six acylhydrazides $(\mathbf{2}, \mathbf{6}$, and $\mathbf{8 a - d})$. Structurally diverse building blocks were chosen for the DCL composition. The equilibration was completed in the presence of $\mathbf{4 b}(2 \mathrm{~h} 30 \mathrm{~min})$ and $\mathbf{4 c}(3 \mathrm{~h})$, whereas the same system in the absence of the catalyst took more than 2 days to equilibrate ( $>16$-fold acceleration). Aldehyde 1 could not be detected in the reaction mixture, indicating that it was continuously being sequestered as an acylhydrazone component. The acylhydrazones were identified by HPLC-MS (see the ESI $\dagger$ ). The reversibility of the DCL was confirmed by setting up consecutive DCLs where a new acylhydrazide was added once the DCL reached its equilibration point. The DCL started with mixing aldehyde $\mathbf{1}$ and four acylhydrazides $\mathbf{6 ,} 8 \mathrm{8a}$, $\mathbf{8 c}$ and $\mathbf{8 d}$. This was followed by the addition of acylhydrazide $\mathbf{2}$ and finally, acylhydrazide $\mathbf{8 b}$ was added, showing an identical distribution to that in Fig. 7, either in the presence of catalyst $\mathbf{4 b}$ or $\mathbf{4 c}$ (see the ESI $\dagger$ ).

\section{Conclusions}

We have reported the study of aniline and three $p$-aniline derivatives as nucleophilic catalysts for acylhydrazone formation in a polar, aprotic solvent, $\mathrm{CD}_{3} \mathrm{CN}$. Kinetic studies by NMR spectroscopy provided the relative rates for each of the two reactions occurring in the catalytic process, with support from quantum mechanical calculations. Comparison of imine and acylhydrazone formation separately showed that the ratelimiting process was always imine formation. para-Substituted anilines $\mathbf{4 b}$ ( $p$-toluidine, $\mathrm{R}=\mathrm{Me})$ and $\mathbf{4 c}$ ( $p$-anisidine, $\mathrm{R}=$ $\mathrm{OMe}$ ) were the most effective catalysts for the reaction between aldehyde 1 and acylhydrazide 2 in acetonitrile solution. The results from the catalytic performance in water at physiological $\mathrm{pH}$ further supported our mechanistic and predictive studies in acetonitrile.

Furthermore, a dynamic combinatorial library with the best performing aniline derivatives, $p$-toluidine (4b) and $p$-anisidine (4c), was set up at physiological $\mathrm{pH}$ and low temperatures. The DCL achieved the required equilibrium composition in $3 \mathrm{~h}$ and $2.5 \mathrm{~h}$, respectively, considerably improving the reported results in the absence of both catalysts. Additionally, taking into account the performance and properties of $p$-anisidine such as water solubility, affordability, and low toxicity, it proves to be an interesting alternative to aniline in systems where biological targets are present.

These efficient catalysts could expand the application of hydrazone-based chemistry, contributing to the development of DCC in biological environments and its use as a hit identification tool in drug discovery.

\section{Experimental section}

\section{Materials and methods}

The chemical reagents $\mathbf{1}, \mathbf{2}$, and $\mathbf{4 a - d}$ and solvents were obtained from commercial sources such as Sigma-Aldrich, Fluorochem and TCI Europe. Microwave-assisted reactions were performed with a Biotage Initiator classic model reactor using sealed vessel tubes with a maximum capacity of $20 \mathrm{~mL}$. The melting point was measured using a Büchi Melting Point M-560 device. ${ }^{1} \mathrm{H}-\mathrm{NMR}$ and ${ }^{13} \mathrm{C}-\mathrm{NMR}$ spectra were recorded using a Bruker NanoBay AVIII $300 \mathrm{MHz}$ spectrometer equipped with a $5 \mathrm{~mm}$ probe BOF and an automation system BACS-60 operated at $300 \mathrm{MHz}$ and $75 \mathrm{MHz}$. Chemical shifts are reported in ppm $(\delta)$, using the corresponding deuterated solvent. Shift multiplicity is denoted as s: single, d: double, and $\mathrm{m}$ : multiplet, and coupling constant values $(J)$ were measured in $\mathrm{Hz}$, acquired in the Nuclear Magnetic Resonance Centre of Complutense University of Madrid. Elemental analysis was performed using a LECO CHNS-932 elemental analyzer of Universidad Complutense de Madrid. HPLC-MS assays were performed by high-performance liquid chromatographymass spectroscopy (HPLC-MS) using an HPLC Surveyor and a Thermo Mod. Finnigan TM LXQ TM ion trap mass spectrometry system (Thermo Mod. Finnigan TM LXQ TM). HPLC solvents and formic acid were obtained from J.T. Baker and Sigma-Aldrich, respectively. Analyses were performed using a reversed phase HPLC column (ACE Excel 3 C18-PFP $4.6 \times$ $100 \mathrm{~mm}, 3 \mu \mathrm{m}$ ) using an injection volume of $25 \mu \mathrm{L}$, a flow rate

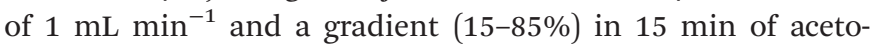
nitrile in water, both containing $0.1 \%$ formic acid at $15{ }^{\circ} \mathrm{C}$. Positive ion mass spectra were obtained using electrospray ionization (drying temperature: $300{ }^{\circ} \mathrm{C}$, sheath gas flow: 60, HV capillary: $6000 \mathrm{~V}$, source voltage: $5.50 \mathrm{kV}$, and source current: $100 \mu \mathrm{A})$.

Synthesis of $(E / Z)-N^{\prime}$-(3-hydroxy-4-nitrobenzylidene)propionohydrazide (3). Over a solution of 3-hydroxy-4-nitrobenzaldehyde $(629 \mathrm{mg}, 3.77 \mathrm{mmol})$ in $\mathrm{MeOH}(60 \mathrm{~mL})$ as a solvent, propanoic acid hydrazide $(300 \mu \mathrm{L}, 2.90 \mathrm{mmol})$ was added. The reaction mixture was stirred at $85{ }^{\circ} \mathrm{C}$ using a heating plate and a DrySyn heating block for $16 \mathrm{~h}$. The crude product was cooled down at room temperature and a yellow amorphous solid precipitated $(0.50 \mathrm{~g}, 65 \%)(E: Z=40: 60)$. M.p: $179-180{ }^{\circ} \mathrm{C}$. 
${ }^{1} \mathrm{H}-\mathrm{NMR}\left(300 \mathrm{MHz}, \mathrm{DMSO}-d_{6}\right) \delta 11.59(\mathrm{~s}, 1 \mathrm{H}, E), 11.44(\mathrm{~s}, 1 \mathrm{H}$, Z), 11.14 (s, $1 \mathrm{H}, E / Z$ ), 8.70 (s, 1H, E), 8.13 (s, 1H, Z), 7.93-7.86 (m, 1H, E/Z), 7.39 (s, 1H, E/Z), 7.27-7.24 (m, 1H, E/Z), 2.65 (q, J $=7.5 \mathrm{~Hz}, 2 \mathrm{H}, Z), 2.23(\mathrm{q}, J=7.5 \mathrm{~Hz}, 2 \mathrm{H}, E), 1.08(\mathrm{t}, J=7.5 \mathrm{~Hz}$, $3 \mathrm{H}, E / Z) .{ }^{13} \mathrm{C}-\mathrm{NMR}\left\{{ }^{1} \mathrm{H}\right\}\left(75 \mathrm{MHz}, \mathrm{DMSO}-d_{6}\right): \delta 176.0,152.8$, $143.7,141.4,140.3,126.4,117.8,116.7,25.7$, 9.1. Anal. calcd for $\mathrm{C}_{10} \mathrm{H}_{11} \mathrm{~N}_{3} \mathrm{O}_{4}$ : C, 50.63\%; H, 4.67\%; N, 17.71\%. Found: C, 50.36\%; H, 4.60\%; N, 17.59\%. HPLC-MS: $t_{\mathrm{R}}: 7.06 \mathrm{~min},[\mathrm{M}+$ $\mathrm{H}]^{+}=238 \mathrm{~m} / \mathrm{z}$.

\section{General procedure for synthesis of imines 5 (a-d)}

A solution of 3-hydroxy-4-nitrobenzaldehyde 1 (1 eq.) and the corresponding amines $\mathbf{4 a - d}$ (1 eq.) was stirred under microwave irradiation at $115{ }^{\circ} \mathrm{C}$ for $30 \mathrm{~min}$ in anhydrous $\mathrm{THF}$ $(12 \mathrm{~mL})$ in a sealed $20 \mathrm{~mL}$ vial. The solvent was removed under reduced pressure and the compounds were afforded as a yellow solid (90-98\%). No further purification was performed.

(E)-2-Nitro-5-((phenylimino)methyl)phenol (5a). 3-Hydroxy4-nitrobenzaldehyde $1(174 \mathrm{mg}, 1.00 \mathrm{mmol})$, aniline (95 $\mu \mathrm{L}$, $1.00 \mathrm{mmol})$, and THF $(12 \mathrm{~mL})$ were used. Yellow amorphous solid. Yield: $240 \mathrm{mg}, 95 \%,(E>99)$. M.p: $99-100{ }^{\circ} \mathrm{C} .{ }^{1} \mathrm{H}-\mathrm{NMR}$ (500 MHz, DMSO- $\left.d_{6}\right): \delta 11.02(\mathrm{~s}, 1 \mathrm{H}), 8.67(\mathrm{~s}, 1 \mathrm{H}), 8.03-7.99$ $(\mathrm{m}, 1 \mathrm{H}), 7.70-7.68(\mathrm{~m}, 1 \mathrm{H}), 7.57-7.38(\mathrm{~m}, 2 \mathrm{H}), 7.40-7.24(\mathrm{~m}$, $3 \mathrm{H}) .{ }^{13} \mathrm{C}-\mathrm{NMR}\left\{{ }^{1} \mathrm{H}\right\}\left(75 \mathrm{MHz}, \mathrm{DMSO}-d_{6}\right): \delta 159.4,152.5,151.0$, 141.9, 138.9, 129.7 (2C), 129.2, 127.2 (2C), 126.2, 121.7, 119.7. Anal. calcd for $\mathrm{C}_{13} \mathrm{H}_{10} \mathrm{~N}_{2} \mathrm{O}_{3}$ : C, 64.46\%; H, 4.16\%; N, 11.56\%. Found: C, 64.63\%; H, 4.27\%; N, 11.42\%.

(E)-2-Nitro-5-(( $p$-tolylimino)methyl)phenol (5b). 3-Hydroxy-4nitrobenzaldehyde (162 mg, $0.9 \mathrm{mmol}), p$-toluidine (100 mg, $0.9 \mathrm{mmol})$, and THF $(12 \mathrm{~mL})$ were used. Yellow amorphous solid. Yield: $220 \mathrm{mg}, 90 \%$, $(E>99)$. M.p: $144-145{ }^{\circ} \mathrm{C} .{ }^{1} \mathrm{H}-\mathrm{NMR}$ $\left(500 \mathrm{MHz}, \mathrm{DMSO}-d_{6}\right): \delta 11.20(\mathrm{~s}, 1 \mathrm{H}), 8.68(\mathrm{~s}, 1 \mathrm{H}), 8.00(\mathrm{~d}, J=$ $8.5 \mathrm{~Hz}, 1 \mathrm{H}), 7.68$ (d, $J=1.6 \mathrm{~Hz}, 1 \mathrm{H}), 7.51$ (dd, $J=8.5,1.6 \mathrm{~Hz}$, 1H), $7.26(\mathrm{~s}, 4 \mathrm{H}), 2.34(\mathrm{~s}, 3 \mathrm{H}) .{ }^{13} \mathrm{C}-\mathrm{NMR}\left\{{ }^{1} \mathrm{H}\right\}(75 \mathrm{MHz}, \mathrm{DMSO}-$ $\left.d_{6}\right): \delta 158.3,152.5,148.3,142.1,138.7,136.9,130.2(2 \mathrm{C}), 126.2$, 121.8 (2C), 119.6, 118.6, 21.1. Anal. calcd for $\mathrm{C}_{14} \mathrm{H}_{12} \mathrm{~N}_{2} \mathrm{O}_{3}: \mathrm{C}$, $65.62 \%$; H, 4.72\%; N, 10.93\%. Found: C, 65.37\%; H, 4.69\%; N, $10.85 \%$.

(E)-5-(((4-Methoxyphenyl)imino)methyl)-2-nitrophenol (5c). 3-Hydroxy-4-nitrobenzaldehyde (124 mg, $0.70 \mathrm{mmol}), p$-anisidine (93 mg, $0.70 \mathrm{mmol}$ ), and THF (12 mL) were used. Yellow amorphous solid. Yield: $190 \mathrm{mg}$, 95\%, ( $E>$ 99). M.p: 143-144 ${ }^{\circ} \mathrm{C}$. ${ }^{1} \mathrm{H}-\mathrm{NMR}\left(500 \mathrm{MHz}, \mathrm{DMSO}-d_{6}\right): \delta 11.14(\mathrm{~s}, 1 \mathrm{H})$, 8.69 (s, 1H), 8.00 (d, $J=8.6 \mathrm{~Hz}, 1 \mathrm{H}), 7.66(\mathrm{~d}, J=1.6 \mathrm{~Hz}, 1 \mathrm{H})$, 7.50 (dd, $J=8.6,1.6 \mathrm{~Hz}, 1 \mathrm{H}), 7.44-7.32$ (m, 2H), 7.07-6.95 (m, $2 \mathrm{H}), 3.80(\mathrm{~s}, 3 \mathrm{H}) .{ }^{13} \mathrm{C}-\mathrm{NMR}\left\{{ }^{1} \mathrm{H}\right\}\left(75 \mathrm{MHz}, \mathrm{DMSO}-d_{6}\right): \delta 159.1$, 156.6, 152.6, 143.6, 142.4, 138.4, 126.2, 123.4 (2C), 119.4, 118.4 (2C), 115.0, 55.8. Anal. calcd. for $\mathrm{C}_{14} \mathrm{H}_{12} \mathrm{~N}_{2} \mathrm{O}_{4}$ : C, 61.76\%; $\mathrm{H}$, $4.44 \%$; N, 10.29\%. Found: C, 61.88\%; H, 4.49\%; N, 10.25\%.

(E)-5-(((4-Bromophenyl)imino)methyl)-2-nitrophenol (5d). 3Hydroxy-4-nitrobenzaldehyde (102 mg, $0.60 \mathrm{mmol})$, 4-bromoaniline (98 mg, $0.60 \mathrm{mmol}$ ), and THF (12 mL) were used. Yellow amorphous solid. Yield: $160 \mathrm{mg}, 98 \%,(E>99)$. M.p: 158-159 ${ }^{\circ} \mathrm{C} .{ }^{1} \mathrm{H}-\mathrm{NMR}\left(500 \mathrm{MHz}, \mathrm{CDCl}_{3}\right): \delta 10.56(\mathrm{~s}, 1 \mathrm{H}), 8.39$ $(\mathrm{m}, 1 \mathrm{H}), 8.12(\mathrm{~m}, 1 \mathrm{H}), 7.63-7.55(\mathrm{~m}, 1 \mathrm{H}), 7.53-7.49(\mathrm{~m}, 1 \mathrm{H})$, 7.48-7.45 (m, 2H), 7.09-7.06 (m, 2H). ${ }^{13} \mathrm{C}-\mathrm{NMR}\left\{{ }^{1} \mathrm{H}\right\}(75 \mathrm{MHz}$,
$\left.\mathrm{CDCl}_{3}\right): \delta 155.5,152.9,147.5,141.6,132.9,130.3$ (2C), 123.6, 120.7 (2C), 118.6, 118.4, 117.4. Anal. calcd for $\mathrm{C}_{13} \mathrm{H}_{9} \mathrm{BrN}_{2} \mathrm{O}_{3}: \mathrm{C}$, $48.62 \%$; H, 2.83\%; N, 8.72\%; found: C, $48.76 \%$;, $2.89 \%$; , $8.67 \%$.

\section{Catalytic study by ${ }^{1} \mathrm{H}-\mathrm{NMR}$}

The pure amine or imine and the aldehyde were dissolved in $500 \mu \mathrm{L}$ of cooled deuterated acetonitrile $\left(\mathrm{CD}_{3} \mathrm{CN}\right)$ in a $5 \mathrm{~mm}$ tube. The final concentrations of the reagents were different for each case (from $16.7 \mathrm{mM}$ to $50 \mathrm{mM}$, each). NMR spectra were obtained on a Bruker AV $500 \mathrm{MHz}$ spectrometer operating at a ${ }^{1} \mathrm{H}$ frequency of $500.13 \mathrm{MHz}$ equipped with a $5 \mathrm{~mm}$ probe head of direct detection. The temperature stability was controlled via a Bruker BCU05 unit and set up to $288 \mathrm{~K}$. The spectrometer was previously stabilized with a sample of similar characteristics (deuterated solvent and sample volume) and shims, tune and match were adjusted. They were not changed during the experiment. All ${ }^{1} \mathrm{H}$ spectra were obtained and processed using the program TOPSPIN 2.1. Once the sample was placed inside the magnet, the reaction was monitored by a ${ }^{1} \mathrm{H}$ spectrum array (600 experiments recorded) for $4.5 \mathrm{~h}$. The acquisition parameters are: number of scans (NS): 8, time domain (TD): $32 \mathrm{~K}$, spectral window (SW): $15 \mathrm{ppm}, \mathrm{O} 1$ : $3000.78 \mathrm{~Hz}$ and relaxation delay (d1): $1 \mathrm{~s}$.

\section{Computational details}

Full geometry optimizations and transition structure (TS) searches were carried out with Gaussian $16^{48}$ using the M06$2 \mathrm{X}$ hybrid functional ${ }^{49}$ and $6-31+\mathrm{G}(\mathrm{d}, \mathrm{p})$ basis set with ultrafine integration grids. Bulk solvent effects in acetonitrile and water were considered implicitly using the IEF-PCM polarizable continuum model. ${ }^{50}$ The possibility of different conformations was taken into account for all structures. All stationary points were characterized by a frequency analysis performed at the same level used in the geometry optimizations from which thermal corrections were obtained at 298.15 K. The quasiharmonic approximation reported by Truhlar et al. was used to replace the harmonic oscillator approximation for the calculation of the vibrational contribution to enthalpy and entropy. ${ }^{51}$ Scaled frequencies were not considered. Massweighted intrinsic reaction coordinate (IRC) calculations were carried out using the Gonzalez and Schlegel scheme ${ }^{52,53}$ in order to ensure that the TSs indeed connected the appropriate reactants and products. Single point energies were calculated at the M06-2X/6-311++G(2d,p) level using the SMD polarizable continuum model. ${ }^{54}$ Zero-point energy, enthalpy and Truhlar's entropy corrections, obtained from the frequency calculation at the $\operatorname{PCM}\left(\mathrm{CH}_{3} \mathrm{CN}\right) / \mathrm{M} 06-2 \mathrm{X} / 6-31 \mathrm{G}(\mathrm{d}, \mathrm{p})$ level, were added to the single point energy calculated at the $\operatorname{SMD}\left(\mathrm{CH}_{3} \mathrm{CN} / \mathrm{H}_{2} \mathrm{O}\right)$ / M06-2X/6-311++G(2d,p) level to give the final reported enthalpy and Gibbs free energy. Relative Gibbs free energies $(\Delta G)$ were used for the discussion on the stabilities of the considered structures. The lowest energy conformer for each calculated stationary point was considered in the discussion; all the computed structures can be obtained from authors upon request. Cartesian coordinates, electronic energies, entropies, enthal- 
pies, Gibbs free energies, and lowest frequencies of the calculated structures are summarized in the ESI. $\dagger$

\section{Hydrazone reaction monitored by HPLC}

The absorbances of aldehyde $\mathbf{1}$ and acylhydrazone 7 were measured. Their concentrations were determined using a calibration curve equation. The reaction in the presence of the catalyst was completed between 3 hours and 4 days depending on the catalyst (4a-5.5 h, $\mathbf{4 b}-4 \mathrm{~h}, \mathbf{4 c}-3 \mathrm{~h}$, and $\mathbf{4 d - 4}$ days). The experiment was performed by the addition of the aldehyde $\mathbf{1}$ $\left(1.8 \mu \mathrm{L}, 50 \mathrm{mM}, 9.0 \times 10^{-8} \mathrm{~mol}\right.$, in DMSO) after preparing the solution of the acylhydrazide $6\left(18 \mu \mathrm{L}, 50 \mathrm{mM}, 9.0 \times 10^{-7} \mathrm{~mol}\right.$, in DMSO), the catalyst $(1.5 \mu \mathrm{L}, 10 \mathrm{M}$ in DMSO) or in the absence of the catalyst, $1.5 \mu \mathrm{L}$ of DMSO, buffer $20 \mathrm{mM}$ Tris, 0.5 $\mathrm{M} \mathrm{NaCl}, 1 \mathrm{mM} \mathrm{CaCl}_{2}$, and $1 \mathrm{mM}$ DTT pH $7.4(950 \mu \mathrm{L})$ using $5 \% \mathrm{v} / \mathrm{v}$ DMSO $(28.7 \mu \mathrm{L})$ at $6{ }^{\circ} \mathrm{C}$. Four $p$-substituent anilines were studied: aniline, $p$-toluidine, $p$-anisidine, and p-bromoaniline.

\section{DCL preparation}

The DCL was set up by mixing Aldehyde $1(1.2 \mu \mathrm{L}, 50 \mathrm{mM}, 6.0$ $\times 10^{-8} \mathrm{~mol}$ in DMSO), 6 acylhydrazides $(2,6$, and $8 \mathbf{a}-\mathbf{d})(6 \times$ $3.6 \mu \mathrm{L}, 50 \mathrm{mM}, 1.8 \times 10^{-7} \mathrm{~mol}$ each in DMSO), $p$-anisidine or $p$-toluidine $\left(1.0 \mu \mathrm{L}, 12 \mathrm{M}, 1.2 \times 10^{-5} \mathrm{~mol}\right.$ in DMSO), DMSO $(10 \mu \mathrm{L})$, buffer $20 \mathrm{mM}$ Tris, $0.5 \mathrm{M} \mathrm{NaCl}, 1 \mathrm{mM} \mathrm{CaCl}_{2}$, and $1 \mathrm{~m}$ M DTT pH $7.4(632 \mu \mathrm{L})$ with 5\% DMSO at $6{ }^{\circ} \mathrm{C}$. Both DCLs were analyzed by HPLC at 3, 4 and 5 hours. Each peak corresponding to acylhydrazones $\mathbf{3}, \mathbf{7}$, and $\mathbf{9 a - d}$ was identified by HPLC-MS and compared to previously synthesized compounds (7 and $\mathbf{9 a - d}){ }^{30}$

\section{Reversibility study}

The addition of each acylhydrazide was performed after the stabilization of the previous mixture. Firstly, aldehyde 1 $\left(1.2 \mu \mathrm{L}, 50 \mathrm{mM}, 6.0 \times 10^{-8} \mathrm{~mol}\right.$, DMSO), four acylhydrazides 6 , 8a, 8c and $8 d\left(4 \times 3.6 \mu \mathrm{L}, 50 \mathrm{mM}, 4 \times 1.8 \times 10^{-7} \mathrm{~mol}\right.$, DMSO $)$, catalyst $4 \mathbf{b}$ or $4 \mathbf{c}\left(1.0 \mu \mathrm{L}, 10 \mathrm{M}, 1.0 \times 10^{-5} \mathrm{~mol}\right.$, DMSO $)$ and DMSO $(6.2 \mu \mathrm{L})$ were mixed in buffer $20 \mathrm{mM}$ Tris, $0.5 \mathrm{M} \mathrm{NaCl}$ and $1 \mathrm{mM} \mathrm{CaCl}_{2}$, and $1 \mathrm{mM}$ DTT pH $7.4(574 \mu \mathrm{L})$ using 5\% v/v DMSO at $6{ }^{\circ} \mathrm{C}$. The DCL was analyzed by HPLC-MS to check the stabilization. Then, acylhydrazide 2 was added $(3.6 \mu \mathrm{L}$, $50 \mathrm{mM}, 1.8 \times 10^{-7} \mathrm{~mol}$, DMSO), and the DCL was analyzed again after 3 hours. Finally, acylhydrazide $8 \mathbf{b}(3.6 \mu \mathrm{L}, 50 \mathrm{mM}$, $1.8 \times 10^{-7} \mathrm{~mol}$, DMSO) was added and analyzed three hours later, affording the same result.

\section{Author contributions}

R. P. F. and G. J. O. conceptualized and supervised the research. A. C. M. performed the chemical experiments. C. D. N. performed the theoretical calculations and analyzed kinetics. E. S. and D. M. performed NMR experiments. R. P. F. and G. J. O. wrote the manuscript with contributions from all authors.

\section{Conflicts of interest}

The authors declare no competing financial interest.

\section{Acknowledgements}

We thank Prof. J. Elguero (IQM-CSIC) for useful discussions. This work was supported by grants from the Spanish Ministry of Science and Innovation (MCI) co-financed with the FEDER funds (PID2019-108587RB-I00 to R. P. F. and RTI2018-099592B-C22 to G. J. O.).

\section{Notes and references}

1 E. M. Sletten and C. R. Bertozzi, Angew. Chem., Int. Ed., 2009, 48, 6974.

2 D. K. Kölmel and E. T. Kool, Chem. Rev., 2017, 117, 10358.

3 W. R. Algar, D. E. Prasuhn, M. H. Stewart, T. L. Jennings, J. B. Blanco-Canosa, P. E. Dawson and I. L. Medintz, Bioconjugate Chem., 2011, 22, 825.

4 X.-G. Li, M. Haaparanta and O. Solin, J. Fluorine Chem., 2012, 143, 49.

5 L. A. Tatum, X. Su and I. Aprahamian, Acc. Chem. Res., 2014, 47, 2141.

6 T. T. Dang, T. T. Dang and P. Langer, Synlett, 2011, 2633.

7 L. H. Yuen, N. S. Saxena, H. S. Park, K. Weinberg and E. T. Kool, ACS Chem. Biol., 2016, 11, 2312.

8 K. Larsen, M. B. Thygesen, F. Guillaumie, W. G. T. Willats and K. J. Jensen, Carbohydr. Res., 2006, 341, 1209.

9 R. Raue, A. Brack and K. Lange, Angew. Chem., Int. Ed. Engl., 1991, 30, 1643.

10 C. Serbutoviez, C. Bosshard, G. Knopfle, P. Wyss, P. Pretre, P. Gunter, K. Schenk, E. Solari and G. Chapuis, Chem. Mater., 1995, 7, 1198.

11 J.-M. Lehn, Angew. Chem., Int. Ed., 2013, 52, 2836.

12 P. Vicini, F. Zani, P. Cozzini and I. Doytchinova, Eur. J. Med. Chem., 2002, 37, 553.

13 X. Su and I. Aprahamian, Chem. Soc. Rev., 2014, 43, 1963.

14 A. Dirksen and P. E. Dawson, Bioconjugate Chem., 2008, 19, 2543.

15 J. Y. Byeon, F. T. Limpoco and R. C. Bailey, Langmuir, 2010, 26(19), 15430.

16 Y. Zeng, T. N. C. Ramya, A. Dirksen, P. E. Dawson and J. C. Paulson, Nat. Methods, 2009, 6, 207.

17 G. H. Stempel and G. S. Schaffel, J. Am. Chem. Soc., 1944, 66(7), 1158.

18 (a) W. P. Jencks, J. Am. Chem. Soc., 1959, 81, 475; (b) E. H. Cordes and W. P. Jencks, J. Am. Chem. Soc., 1962, 84, 827; (c) E. H. Cordes and W. P. Jencks, J. Am. Chem. Soc., 1962, 84, 4319; (d) W. P. Jencks, Prog. Phys. Org. Chem., 1964, 2, 63.

19 E. T. Kool, D. H. Park and P. Crisalli, J. Am. Chem. Soc., 2013, 47, 17663. 
20 J. M. Sayer, M. Peskin and W. P. Jencks, J. Am. Chem. Soc., 1973, 95, 4277.

21 J. Kalia and R. T. Raines, Angew. Chem., Int. Ed., 2008, 47, 7523.

22 S. J. Rowan, S. J. Cantrill, G. R. L. Cousins, J. K. M. Sanders and J. F. Stoddart, Angew. Chem., Int. Ed., 2002, 41, 898.

23 O. Ramström and J.-M. Lehn, Nat. Rev. Drug Discovery, 2002, 1, 26.

24 A. Canal-Martín and R. Pérez-Fernández, ACS Omega, 2020, 5, 26307.

25 A. Dirksen, S. Dirksen, T. M. Hackeng and P. E. Dawson, J. Am. Chem. Soc., 2006, 128, 15602.

26 V. T. Bhat, A. M. Caniard, T. Luksch, R. Brenk, D. J. Campopiano and M. F. Greaney, Nat. Chem., 2010, 2, 490.

27 A. R. Blanden, K. Mukherjee, O. Dilek and S. L. Bane, Bioconjugate Chem., 2011, 22, 1954.

28 P. Crisalli and E. T. Kool, J. Org. Chem., 2013, 78, 1184.

29 P. Crisalli and E. T. Kool, Org. Lett., 2013, 15, 11646.

30 A. Canal-Martín, J. Sastre, M. J. Sanchez-Barrena, A. Canales, S. Baldominos, N. Pascual, L. MartínezGonzález, D. Molero, M. E. Fernández-Valle, E. Sáez, P. Blanco, E. Gomez, S. Martín-Santamaría, A. Sáiz, A. Mansilla, F. J. Cañada, J. Jiménez-Barbero, A. Martínez and R. Pérez-Fernández, Nat. Commun., 2019, 10, 2798.

31 I. N. Levine, Physical Chemistry, Mc Graw Hill, USA, 5th edn, 2004, ch. 17, vol. (II).

32 P. L. Higgs, A. Ruiz-Sanchez, M. Dalmina, B. R. Horrocks, A. G. Leach and D. A. Fulton, Org. Biomol. Chem., 2019, 17, 3218.

33 R. Nguyen and I. Huc, Chem. Commun., 2003, 942.

34 D. W. Domaille and J. N. Cha, Chem. Commun., 2014, 50, 3831.

35 S. Kulchat, M. N. Chaur and J.-M. Lehn, Chem. - Eur. J., 2017, 23, 11108.

36 C. G. Swain, A. L. Powell, W. A. Sheppard and C. R. Morgan, J. Am. Chem. Soc., 1979, 101(13), 3576.

37 F. López-Calahorra and R. A. Rubires, Tetrahedron, 1995, 51, 9713.

38 V. C. Rufino and J. R. Pliego, Comput. Theor. Chem., 2020, 1191, 113053.

39 V. C. Rufino and J. R. Pliego, Asian J. Org. Chem., 2021, 10, 1472.

40 L. Hong, W. Sun, D. Yang, G. Li and R. Wang, Chem. Rev., 2016, 116, 4006-4123.
41 Q. Yang, Y. Li, Y. Liu, L. Zhang, S. Luo and J.-P. Cheng, Angew. Chem., Int. Ed., 2020, 59, 19282-19291.

42 J.-D. Yang, X.-S. Xue, P. Ji, X. Li and J.-P. Cheng, Internet Bond-energy Databank ( $\mathrm{p} K_{\mathrm{a}}$ and BDE):/BonD Home Page http://ibond.chem.tsinghua.edu.cnor http://ibond.nankai. edu.cn.

43 J. F. Coetzee and G. R. Padmanabhan, J. Phys. Chem., 1965, 69, 3193-3196.

44 J. Jover, R. Bosque and J. Sales, QSAR Comb. Sci., 2008, 27, 563-581.

45 V. C. Rufino and J. R. Pliego, ARKIVOC, 2020, part ii, 34-52.

46 M. Ciaccia and S. Di Stefano, Org. Biomol. Chem., 2015, 13, 646-654.

47 M. Ciaccia, R. Cacciapaglia, P. Mencarelli, L. Mandolini and S. Di Stefano, Chem. Sci., 2013, 4, 2253-2261.

48 M. J. Frisch, G. W. Trucks, H. B. Schlegel, G. E. Scuseria, M. A. Robb, J. R. Cheeseman, G. Scalmani, V. Barone, G. A. Petersson, H. Nakatsuji, X. Li, M. Caricato, A. V. Marenich, J. Bloino, B. G. Janesko, R. Gomperts, B. Mennucci, H. P. Hratchian, J. V. Ortiz, A. F. Izmaylov, J. L. Sonnenberg, D. Williams-Young, F. Ding, F. Lipparini, F. Egidi, J. Goings, B. Peng, A. Petrone, T. Henderson, D. Ranasinghe, V. G. Zakrzewski, J. Gao, N. Rega, G. Zheng, W. Liang, M. Hada, M. Ehara, K. Toyota, R. Fukuda, J. Hasegawa, M. Ishida, T. Nakajima, Y. Honda, O. Kitao, H. Nakai, T. Vreven, K. Throssell, J. A. Montgomery Jr., J. E. Peralta, F. Ogliaro, M. J. Bearpark, J. J. Heyd, E. N. Brothers, K. N. Kudin, V. N. Staroverov, T. A. Keith, R. Kobayashi, J. Normand, K. Raghavachari, A. P. Rendell, J. C. Burant, S. S. Iyengar, J. Tomasi, M. Cossi, J. M. Millam, M. Klene, C. Adamo, R. Cammi, J. W. Ochterski, R. L. Martin, K. Morokuma, O. Farkas, J. B. Foresman and D. J. Fox, Gaussian 16, Revision B.01, Gaussian, Inc., Wallingford CT, 2016.

49 Y. Zhao and D. G. Truhlar, Theor. Chem. Acc., 2008, 120, 215. 50 G. Scalmani and M. J. Frisch, J. Chem. Phys., 2010, 132, 114110.

51 R. F. Ribeiro, A. V. Marenich, C. J. Cramer and D. G. Truhlar, J. Phys. Chem. B, 2011, 115, 14556.

52 C. Gonzalez and H. B. Schlegel, J. Chem. Phys., 1989, 90, 2154.

53 C. Gonzalez and H. B. Schlegel, J. Phys. Chem., 1990, 94, 5523.

54 A. V. Marenich, C. J. Cramer and D. G. Truhlar, J. Phys. Chem. B, 2009, 113, 6378. 